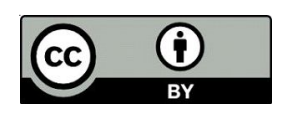

Submitted: 18.03.2021

Accepted: 08.04.2021

\title{
RETAIL INVESTMENT FINANCING VIA REMOTE DIGITAL COMPUTER ALGORITHM ${ }^{1}$
}

\author{
Denis E. Matytsin \\ Volgograd State University, Volgograd, Russian Federation
}

\begin{abstract}
Introduction: in the paper, the author examines the activities of the Russian legislators on the formation of the legal regulation of the investment segment of the economy in order to identify their mistakes and shortcomings, as well as to justify the recommendations for fixing viable legal structures in the legislation. Such legitimate structures could be used by a wide range of individual investors-individuals - as part of their decision to diversify monetary investments in order to increase household savings for a period of 1 year or more. Methodology: the digital computer algorithms of inter-network interaction for placement and attraction of investments, their speed and independence from distance are perceived by entrepreneurs with great hope for success and attract more and more attention from investors. According to the author of the paper, by 2024, the financial digital technologies can replace up to $38 \%$ of traditional banking and payment transactions, up to $32 \%$ of insurance transactions, transactions for financing foreign trade transactions, and transactions for asset management. Based on the materialist worldview, the universal method of historical materialism, the author used the general scientific and specific scientific methods for the study, which made it possible to implement a systematic approach to the subject of research. The general scientific methods of cognition are applied: the dialectical, hypothetical-deductive methods, generalization, induction and deduction, analysis and synthesis, empirical description. The research also uses the specific scientific methods: dogmatic, comparative-legal, hermeneutic, structural-functional, etc. The scientific development of the material is carried out on the basis of a set of normative and doctrinal sources. The paper uses the federal laws and other normative acts of the Russian Federation. Federal Law No. 259-FZ of August 2, 2019 "On Attracting Investments Using Investment Platforms and on Amendments to Certain Legislative Acts of the Russian Federation", Draft Federal Law No. 419090-7 "On Alternative Methods of Attracting Investments (Crowdfunding)", and certain provisions of the Civil Code of the Russian Federation were studied. Draft Law No. 419059-7 “On Digital Financial Assets" of March 20, 2018, and Federal Law No. 34-FZ of March 18, 2019 "On Amendments to Parts One, Two, and Article 1124 of Part Three of the Civil Code of the Russian Federation" were critically analyzed. The doctrinal sources are represented by the scientific publications of the Russian legal scholars and economists, including: A.O. Inshakova, A.E. Kalinina, A.I. Goncharov, M.V. Goncharova, O.P. Kazachenok, E.E. Frolova, etc. Results: the Internet investing provides an opportunity to obtain funding for the implementation of a publicly announced project relatively quickly and without bureaucratization. The absence of the geographical and distance restrictions is a special advantage of investing on the Internet platforms, compared to other tools for raising capital from a wide range of investors, including individuals. This remote Internet algorithm for retail investment financing allows you to attract capital at a price that corresponds to the profitability of projects and, as a rule, is lower than the average bank interest rate for a loan. Conclusions: the conclusions and assessments on the content of the new Russian legislation are formulated. Based on the critical analysis of the scientific works of the economists and lawyers, the authors formulate the definitions of a special algorithm for remote investments from a wide range of subjects, as well as the tools for remote interaction of investors and investment organizers in the Internet space of modern Russia.
\end{abstract}

Key words: digital space, remote computer algorithms, civil law, law; retail investments, crypto records, the $\vec{\widetilde{ }}$ Internet investing. 


\title{
РОЗНИЧНОЕ ФИНАНСИРОВАНИЕ ИНВЕСТИЦИЙ ПОСРЕДСТВОМ ДИСТАНЦИОННОГО ЦИФРОВОГО КОМПЬЮТЕРНОГО АЛГОРИТМА ${ }^{1}$
}

\author{
Денис Евгеньевич Матыцин \\ Волгоградский государственный университет, г. Волгоград, Российская Федерация
}

\begin{abstract}
Введение: в статье автор исследует деятельность российских законодателей по формированию правового регулирования инвестиционного сегмента экономики с целью выявления их ошибок и недоработок, а также для обоснования рекомендаций по закреплению в законодательстве жизнеспособных правовых конструкций. Такие легитимные конструкции могли бы использоваться широким кругом индивидуальных инвесторов - физических лиц в рамках решения ими задачи диверсификации денежных вложений с целью приращения сбережений домохозяйств на срок в пределах 1 года и более. Методология: цифровые компьютерные алгоритмы межсетевого взаимодействия для размещения и привлечения инвестиций, их скорость и независимость от расстояния с большой надеждой на успех воспринимаются предпринимателями и все большее внимание привлекают со стороны инвесторов. По оценкам автора статьи, к 2024 г. финансовые цифровые технологии могут заменить до 38 \% традиционных банковских и платежных операций, до 32 \% страховых операций, сделок по финансированию внешнеторговых сделок, сделок по управлению активами. Опираясь на материалистическое мировоззрение, всеобщй метод исторического материализма, автор использовал для исследования общенаучные и частнонаучные методы, что позволило реализовать системный подход к предмету исследования. Применены общенаучные методы познания: диалектический, гипотетико-дедуктивный метод, обобщение, индукция и дедукция, анализ и синтез, эмпирическое описание. В исследовании использованы также частнонаучные методы: догматический, сравнительно-правовой, герменевтический, структурно-функциональный и другие. Научная разработка материала осуществлена на основе комплекса нормативных и доктринальных источников. В статье использованы федеральные законы и иные нормативные акты Российской Федерации. Исследовались Федеральный закон от 02.08.2019 № 259-Ф3 «О привлечении инвестиций с использованием инвестиционных платформ и о внесении изменений в отдельные законодательные акты Российской Федерации», Проект Федерального закона № 419090-7 «Об альтернативных способах привлечения инвестиций (краудфандинге)», отдельные положения Гражданского кодекса Российской Федерации. Критически анализировались Законопроект № 419059-7 «О цифровых финансовых активах» от 20 марта 2018 г., Федеральный закон от 18.03.2019 № 34-Ф3 «О внесении изменений в части первую, вторую и статью 1124 части третьей Гражданского кодекса Российской Федерации». Доктринальные источники представлены научными публикациями отечественных правоведов и экономистов, в их числе: А.О. Иншакова, А.Э. Калинина, А.И. Гончаров, М.В. Гончарова, О.П. Казаченок, Е.Е. Фролова и др. Результаты: интернет-инвестинг предоставляет возможность относительно быстрого и не бюрократизированного получения финансирования для реализации публично заявленного проекта. Отсутствие географических и дистанционных ограничений - особое преимущество инвестирования на интернет-платформах, по сравнению с другими инструментами привлечения капитала от широкого круга инвесторов, включая физических лиц. Такой дистанционный интернет-алгоритм розничного финансирования инвестиций позволяет привлекать капиталы по цене, которая соответствуют рентабельности проектов и, как правило, ниже средней ставки банковского процента за кредит. Выводы: сформулированы выводы и оценки по содержанию нового российского законодательства. На основе критического анализа научных работ экономистов и юристов авторами сформулированы дефиниции специального алгоритма удаленных инвестиций от широкого круга субъектов, а также инструментов дистанционного взаимодействия инвесторов и организаторов инвестирования в интернет-пространстве современной России.
\end{abstract}

Ключевые слова: цифровое пространство, дистанционные компьютерные алгоритмы, гражданское право, закон, розничные инвестиции, криптозаписи, интернет-инвестинг.

Цитирование. Матыцин Д. Е. Розничное финансирование инвестиций посредством дистанционного цифрового компьютерного алгоритма // Legal Concept = Правовая парадигма. -2021 . - Т. 20, № 2. - C. 150-158. DOI: https://doi.org/10.15688/lc.jvolsu.2021.2.20 


\section{Введение}

Внешнеторговые сделки, интенсивность которых между хозяйствующими субъектами в последнее пятилетие заметно возросла, требуют, как правило, привлечения крупных финансовых ресурсов. Денежные средства уплачиваются за товары и их доставку в страну покупателя, затем с прибылью возвращаются поставщику по сделке [3, с. 375-393]. В подобных ситуациях классическое банковское кредитование не всегда приемлемо для организаторов сделки. Вполне эффективным инструментом финансового обеспечения серии повторяющихся внешнеторговых сделок является целевое финансирование от группы инвесторов, причем денежные средства можно привлекать дистанционно, применяя новые цифровые технологии. Быстрота и независимость от расстояний, в частности цифровых алгоритмов интернет-взаимодействия для привлечения инвестиций, с большой надеждой на успех восприняты предпринимателями. По нашим оценкам, к 2024 г. финансовые цифровые технологии могут заменить до 38 \% традиционного банкинга и платежей, до $32 \%$ страховых операций, сделок по финансированию внешнеторговых сделок, сделок по управлению активами. Возникла новая индустрия цифровой финтех (финансовые цифровые технологии), финтех строится на особом компьютерном программном фундаменте - это блокчейн и смарт-контракты, которые обеспечивают высокую скорость, анонимность, децентрализованность и криптозащиту ведения операций в Интернете [15, с. 205-213].

Традиционных инструментов для получения инвестиций в современных условиях становится объективно недостаточно [12, с. 3142]. Развитие электронных технологий, возникновение и стремительный рост популярности сначала «электронных денег», а в последние годы - оборачивающихся в Интернете криптозаписей - предопределило появление в международной финансовой практике способа инвестирования, связанного с вложением в перспективные проекты средств, получаемых от широкого круга инвесторов. Многообразие предлагаемых инвесторам проектов, конкуренция в целом ряде сегментов современной экономики (IT-технологии, рынок услуг связи, телекоммуникации и др.) обусловливают то, что компании прибегают к использованию более удобных и эффективных инструментов и источников финансирования своих программ и проектов [1, с. 606-625]. Одним из таких является интернет-инвестинг - дистанционный компьютерный алгоритм розничного привлечения и размещения капитала через специальные инвестиционные платформы, легитимно функционирующие в информационно-телекоммуникационной сети Интернет.

\section{Результаты}

Во второй половине 2018 г. в Государственной Думе Федерального собрания Российской Федерации находилось 3 законопроекта, касающихся цифровой сферы: «О цифровых финансовых активах», «Об альтернативных способах привлечения инвестиций (краудфандинге)» и «О внесении изменений в части первую, вторую и четвертую Гражданского кодекса Российской Федерации» [8].

Основная проблема подготовленных законопроектов была в том, что они не соотносились с действующим гражданским и налоговым законодательством, законодательством о рынке ценных бумаг, об организованных торгах. Можно в целом поддержать положения законопроектов по защите инвесторов, но ограничения по сумме вложений для неквалифицированных инвесторов, обязательность совершения операций через оператора обмена вредны для инвестиционного рынка [13, с. 101-108]. Однако положение о передаче собственного ключа от цифрового кошелька третьему лицу противоречит самой сути децентрализованного криптопространства.

Рациональным и продуманным выглядит регулирование в Федеральном законе от 02.08.2019 № 259-Ф3 «О привлечении инвестиций с использованием инвестиционных платформ и о внесении изменений в отдельные законодательные акты Российской Федерации» (Закон об инвестициях с использованием инвестиционных платформ) - ранее законопроект «Об альтернативных способах привлечения инвестиций (краудфандинге)». Закон об инвестициях с использованием инвестиционных платформ закрепляет сложившиеся и положительно зарекомендовавшие 
себя на рынке способы привлечения финансирования в различные проекты. Ключевыми акцентами мы считаем требования к инвестиционным платформам и операторам этих платформ, требования к инвесторам, а также - к инвестиционным проектам и к получателям инвестиций. Операторы инвестиционных платформ будут включаться в специализированный реестр Банка России. Для них установлены требования к размеру собственных средств (не менее 5 млн руб.). Также законодателем установлены требования к органам управления, к бенефициарам, к раскрытию информации, требования к наличию достоверного реестра договоров, заключенных на данной инвестиционной платформе, требования к расположению основных и резервных датацентров, которые должны находиться на территории Российской Федерации [10].

Усилен законодательный подход к ответственности оператора инвестиционной платформы - установлена обязанность возмещения участникам инвестиционной платформы убытков, причиненных вследствие предоставления недостоверной, неполной или вводящей в заблуждение информации об инвестиционной платформе и ее операторе, а также за нарушение правил инвестиционной платформы. В защиту интересов инвесторов устанавливаются требования к их идентификации, вводятся ограничения по размеру инвестиций в течение одного календарного года - не более 50 тыс. руб. для одного инвестора в один инвестиционный проект. Также вводятся ограничения для граждан - не более 600 тыс. руб. на всех инвестиционных платформах в год. При этом хозяйствующий субъект, привлекающий инвестиции, может привлечь не более 1 млрд руб. в течение календарного года на всех инвестиционных платформах. В зарубежной практике тоже устанавливается предел суммы инвестиций в один проект от одного инвестора, а также ограничение общей суммы инвестиций в проект. В европейских юрисдикциях (Германия, Франция, Испания) сумма инвестиций в один проект ограничивается в диапазоне от 2.5 до 5 млн евро, сумма от одного инвестора, в зависимости от его квалификации может составлять от 1 до 10 тыс. евро.

Формально основная цель принятия законопроекта - защита прав и законных инте- ресов инвесторов. Для этого в качестве обязательного условия оферты лица, привлекающего инвестиции, о заключении договора об инвестировании, является указание минимального объема привлекаемых денежных средств. Если этот объем не собран в течение срока оферты, предусматривается отзыв оферты и возврат инвесторам денежных средств. К защитным мерам относится установление срока, в течение которого инвестор вправе отозвать вложенные деньги. Соблюдение указанных ограничений должен контролировать сам оператор инвестиционной платформы. Положительно, что Закон об инвестициях с использованием инвестиционных платформ предусматривает, что интернет-инвестинг - на русском юридическом языке народное финансирование - можно варьировать. Привлечение-размещение капитала может осуществляться как традиционными способами [предоставление займов; приобретение эмиссионных ценных бумаг, размещаемых с использованием инвестиционной платформы (кроме ценных бумаг кредитных организаций, некредитных финансовых организаций, кроме структурных облигаций и предназначенных для квалифицированных инвесторов ценных бумаг)], так и путем приобретения утилитарных цифровых прав.

Следует также одобрить отказ законодателя в Законе об инвестициях с использованием инвестиционных платформ от термина «тукен», который мы критически исследовали [14, с. 337-342]. В действующем тексте указанного закона закреплен термин «утилитарное цифровое право» - это криптозапись в базе данных инвестиционной платформы, которая может удостоверять требования, возникающие из различных договоров. В частности, это может быть требование передачи вещи (вещей); требование передачи исключительных прав на результаты интеллектуальной деятельности или прав использования результатов интеллектуальной деятельности; требование выполнения работ; требование оказания услуг (за исключением требования передачи имущества, права на которое подлежат государственной регистрации, также за исключением требования передачи имущества, сделки с которым подлежат государственной регистрации или нотариальному удо- 
стоверению). Фактическое получение предоставления по требованию возможно инвестором лично, возможно через посредника (в классическом варианте - через брокера), которым является оператор инвестиционной платформы.

Согласно Закону об инвестициях с использованием инвестиционных платформ интернет-инвестинг допускается только путем вложения безналичных денежных средств, которые зачисляются на отдельный счет, открытый в кредитной организации оператору инвестиционной платформы. Отношения между оператором инвестиционной платформы и ее участниками возникают на основании двух видов договоров. Первый вид договора - об оказании услуг по привлечению инвестиций. Второй - об оказании услуг по содействию инвестированию. Они являются договорами присоединения. Оператор инвестиционной платформы оказывает услуги согласно Правилам, размещенным на своем сайте в информационно-телекоммуникационной сети Интернет. В Правилах должны быть обозначены требования к проектам, которые могут быть инвестированы с помощью инвестиционной платформы; требования к лицам, привлекающим инвестиции; способы осуществления инвестиций; формы примерных договоров и иная информация.

Закон об инвестициях с использованием инвестиционных платформ в ст. 17 предусматривает ведение Банком России реестра операторов инвестиционных платформ. Ограничивается круг субъектов, которые вправе привлекать инвестиции на инвестиционных платформах: только юридические лица, созданные по законодательству Российской Федерации, индивидуальные предприниматели, если в отношении них в арбитражный суд не подано заявление о признании банкротом. Оператор инвестиционной платформы получил право самостоятельно устанавливать дополнительные требования к лицам, привлекающим инвестиции. По нашему мнению, это неработающая норма, поскольку во всех случаях оператор инвестиционной платформы не отвечает перед инвесторами по обязательствам лица, привлекающего инвестиции [11, с. 147-153].

Положительно, что российские законодатели отказались от слова «краудфандинг» в названии и в тексте Закона об инвестициях с использованием инвестиционных платформ. Понятие краудфандинга заимствовано из английского языка (crowd - толпа, funding - финансирование), возникло в 2006 г., его авторство приписывают журналисту Джеффу Хоу [5, с. 140-145]. В юридической доктрине выработаны некоторые трактовки этого инвестиционного алгоритма. Например, В.А. Кузнецов определяет краудфандинг как деятельность, которая связана с привлечением финансовых ресурсов большого количества людей, добровольно объединяющих свои деньги на специализированных интернет-сайтах (краудфандинговых площадках) в целях реализации продукта или услуги [6, с. 65-73]. С.С. Тропская утверждает, что краудфандинг - это технология коллективного финансирования, в рамках которой осуществляется сбор денежных средств для реализации проекта за счет привлечения широкого круга вкладчиков - добровольцев [9, с. 28-33]. В законопроекте о краудфандинге его дефиниция отсутствовала, при этом раскрывалась деятельность инвестиционных платформ - это услуга по организации розничного финансирования и далее в скобках было указано - краудфандинг [2, c. 49-56].

В 2019 г. за рубежом вполне успешно функционировали краудфандинговые интернетресурсы «KickStarter», «Indiegogo.com», «SeedRS.com», «Crowd-cube.com», «Startmarket.net», «Equity.net». В Российской Федерации в начале 2019 г. действует более 30 платформ коллективного финансирования, например: «Boomstarter.ru», «Planeta.ru», «Kroogi», «ThankYou.ru», «Together», «Naparanet», «StartTrack», «CrowdPress», «Мой учитель», «С миру по нитке», «Руфандер», «Русини», «Стартмен», «Стартиум». По нашим оценкам, за несколько лет работы краудфандинговые площадки в России смогли привлечь инвестиций не менее 1 млрд рублей. Вследствие многообразия инвестиционных проектов сформировались различные виды инвестиций по интернет-площадкам. Договоры, заключаемые при помощи инвестиционных платформ, в научной литературе классифицируют по правам, которые возникают у инвестора после перевода денежной суммы лицу, привлекающему инвестиции. Практичес- 
ки все российские авторы описывают одни и те же модели краудфандинга. Например, Д.А. Котенко выделяет 3 разновидности краудфандинга, 5 разновидностей - В.А. Кузнецов и А.О. Клинов [4, с. 90-105].

Мы интегрируем имеющиеся концепции в 4 алгоритма инвестиций по интернетплощадкам:

1. Безвозмездный интернет-инвестинг. Не следует думать, что инвестор не получает никакого встречного предоставления, хотя законодательство предусматривает такой вариант даже для юридических лиц, для которых безвозмездные сделки не характерны. Так, в Письме Федеральной налоговой службы 2016 г. проводится аналогия безвозмездного получения имущества посредством краудфандинга с пожертвованием (ст. 582 ГК РФ), то есть дарением вещи или права в общеполезных целях. При этом пожертвование имущества юридическим лицам может быть обусловлено жертвователем использованием этого имущества по определенному назначению. То же самое происходит, если конечный пользователь предлагаемого на указанной инвестиционной платформе проекта решает вложить деньги именно в его реализацию [7]. В подобных ситуациях встречное предоставление имеет условный, неэквивалентный характер: сувениры, упоминания на интернет-сайте, упоминания в проектном продукте, получение товара, который будет выпущен в итоге проекта. Однако полностью благотворительные проекты тоже финансируются посредством интернет-инвестинга. Так, в Интернете широко распространилась история 3. Брауна, который при помощи американской платформы «Kickstarter» пытался привлечь сумму в 10 долл. США для приготовления картофельного салата лично для себя. Реально за несколько дней интернет-инвестинга объем привлеченных денежных средств превысил 60000 долл. США. По мере увеличения количества денежных поступлений Зак Браун корректировал свой «проект», увеличивая количество рецептов и порций, которые он собирался приготовить, улучшая качество и увеличивая стоимость продуктов - ингредиентов для салата, предлагая провести интернет-трансляцию из кухни.

2. Встречно-возвратный интернет-инвестинг. Этот вид дистанционных вложений пре- дусматривает получение готовой продукции проекта в обмен на вклад в стартап. Указанный тип договора интернет-инвестинга напоминает договор купли-продажи с предварительной оплатой товара. Условно-возвратный интернет-инвестинг широко используется в сфере разработки компьютерных игр и иного программного обеспечения. Однако как исключение в числе крупных продуктовых инвестиционных проектов известен проект производства надувных диванов «Биван».

3. Корпоративный интернет-инвестинг. При таком варианте дистанционных вложений в обмен на денежные средства инвестор получает долю в бизнесе: становится соучредителем общества с ограниченной ответственностью, получает пакет акций, дивиденды и др.

4. Заемный интернет-инвестинг. Данный вид дистанционных вложений предусматривает сбор денежных средств с целью финансирования юридических и физических лиц на условиях возврата. Этот алгоритм аналогичен кредитованию, в случае если дополнительно к сумме основного вклада инвестору возвращаются еще и проценты.

Субъектный состав юридической конструкции интернет-инвестинга для всех его разновидностей следующий: 1) получатель финансирования; 2) инвестор; 3) оператор инвестиционной платформы - организация, предоставляющая участникам инвестиционной платформы доступ к ее информационным ресурсам и ведущая специализированные счета по взаиморасчетам. При возникновении конфликтных ситуаций, связанных со сделками через инвестиционные платформы, следует опираться на общие положения ГК РФ, а также на положения специальных законов, регулирующих виды заключаемых договоров. Кроме того, на инвестиционные платформы распространяется законодательство об информационном посреднике (ст. 1253.1 ГК РФ), об ограничении информации об экстремизме, суициде, распространении наркотиков и иной запрещенной информации. По нашему мнению, для российского Закона об инвестициях с использованием инвестиционных платформ осуществлена вполне разумная рецепция некоторых зарубежных моделей правового регулирования краудфандинга, в частности, таких 
стран, как Германия, Франция, Испания, это обоснованно, поскольку указанные юрисдикции находятся в общей с Россией романо-германской правовой семье.

Как отмечено ранее, получатель инвестиций помимо привлечения заемного капитала, размещения долговых, долевых ценных бумаг имеет узаконенное право предлагать инвесторам утилитарные цифровые права. Законом об инвестициях с использованием инвестиционных платформ предусмотрен депозитарный учет утилитарных цифровых прав, а также возможность их секьюритизации. Получатель инвестиций вправе выпускать ценные бумаги, удостоверяющие эти утилитарные цифровые права - цифровые свидетельства. Они представляют собой неэмиссионные, не имеющие номинальной стоимости бездокументарные ценные бумаги, удостоверяющие факт принадлежности владельцу свидетельства того или иного утилитарного цифрового права. Его выдача депозитарием не требует государственной регистрации, депозитарий на основании договора получает возможность распоряжаться утилитарным цифровым правом, оказывать услуги по осуществлению утилитарного цифрового права и (или) по распоряжению им определенным образом.

Следует полностью поддержать такой подход законодателя, позволяющий использовать существующую инфраструктуру для организации оборота утилитарных цифровых прав на рынке инвестиционных инструментов современной России.

\section{Заключение}

Главным преимуществом интернет-инвестинга является возможность относительно быстро и без тяжелых бюрократических процедур получать финансирование для реализации заявленных проектов. Отсутствие географических и дистанционных ограничений - еще одно его важное преимущество, в сравнении с другими инструментами привлечения капитала. Данный дистанционный интернет-алгоритм розничного финансирования инвестиций позволяет привлекать капиталы по цене, которая соответствует рентабельности проектов. Финансовые отношения устанавли- ваются с инвесторами практически со всего мира, получатели инвестиций после освоения финансовых ресурсов и реализации своих проектов будут снова и снова выходить на инвестиционные площадки с новыми идеями, доходы участников проектов и экономика в целом будут расти.

\section{ПРИМЕЧАНИЕ}

${ }^{1}$ Исследование выполнено за счет гранта Российского научного фонда (проект № 20-18-00314).

The work was supported by Russian Science Foundation (project № 20-18-00314).

\section{СПИСОК ЛИТЕРАТУРЫ}

1. Ермакова, Е. П. Правовое регулирование цифрового банкинга в России и зарубежных странах (Европейский Союз, США, КНР) / Е. П. Ермакова, Е. Е. Фролова // Вестник Пермского университета. Юридические науки. - 2019. - № 46. - С. 606-625.

2. Иншакова, А. О. Императивы финансовой политики в условиях цифровизации российской экономики / А. О. Иншакова, А. И. Гончаров // Банковское право. - М. : Юрист, 2018. № 2. - C. 49-56.

3. Иншакова, А. О. Коносамент в правовом обеспечении внешнеторговой деятельности: от личной выписки до электронного криптокода / А. О. Иншакова, А. И. Гончаров // Вестник РУДН. - 2019. - Т. 23, № 3.C. 375-393.

4. Клинов, А. О. Правовое регулирование краудфандинга в России и за рубежом / А. О. Клинов // Закон. - 2018. - № 2. - С. 90-105.

5. Котенко, Д. А. Краудфандинг - инновационный инструмент инвестирования / Д. А. Котенко // Закон. - 2014. - № 5. - С. 140-145.

6. Кузнецов, В. А. Краудфандинг: актуальные вопросы регулирования / В. А. Кузнецов // Деньги и кредит. -2017 . - № 1. - С. 65-73.

7. Письмо Федеральной налоговой службы от 25.11.2016 № СД-4-3/22415@. - Электрон. текстовые дан. - Режим доступа: http://nalog.ru (дата обращения: 20.11.2019). - Загл. с экрана.

8. Проект Федерального закона № 419090-7 «Об альтернативных способах привлечения инвестиций (краудфандинге)». - Электрон. текстовые дан. - Режим доступа: https://sozd.duma.gov.ru/bill/ 419090-7. - Загл. с экрана.

9. Тропская, С. С. Финансовый рынок в условиях развития цифровой экономики (финансовоправовой аспект) / С. С. Тропская // Финансовое право. - 2018. - № 8. - С. 28-33. 
10. Федеральный закон от 02.08.2019 № 259-Ф3 «О привлечении инвестиций с использованием инвестиционных платформ и о внесении изменений в отдельные законодательные акты Российской Федерации» // Собрание законодательства РФ. - 2019. 5 авг. (№ 31). - Ст. 4418.

11. Amendments to the Civil Code of the Russian Federation: Contradictions of Theory and Practice / A. O. Inshakova [et al.] // Contributions to Economics. Russia and the European Union: Development and Perspectives Number XIII. - 2017. - P. 147-153.

12. Goncharov, A. I. Digital Tokens in the Tools of Modern Foreign Trade Activities by Economic Entities of the BRICS Jurisdictions / A. I. Goncharov, M. V. Goncharova // Legal Concept = Pravovaya paradigma. -2019. - Vol. 18, no. 3. - P. 31-42. -DOI: https://doi.org/10.15688/lc.jvolsu.2019.3.5.

13. Frolova, E. E. The Concept and Legal Framework for Judging Corporate Conflicts on the US Financial Market / E. E. Frolova, A. O. Inshakova, V. V. Dolinskaya // "Conflict-Free" Socio-Economic Systems: Perspectives and Contradictions. - Bingley : West Yorkshire, 2019. - P. 101-108.

14. Inshakova, A. O. The Imperatives of Financial Policy in the Sphere of the Digital Economy: Impacts on Increasing Investment Activity and Tax Potential of Russian Regions / A. O. Inshakova, A. I. Goncharov, O. P. Kazachenok // Proceedings of the International Scientific Conference «Competitive, Sustainable and Secure Development of the Regional Economy: Response to Global Challenges» (CSSDRE 2018). Amsterdam : Atlantis Press, 2018. - P. 337-342.

15. Kalinina, A. E. Polysubject Jurisdictional Blockchain: Electronic Registration of Facts to Reduce Economic Conflicts. Ubiquitous Computing and the Internet of Things: Prerequisites for the Development of ICT / A. E. Kalinina, A. O. Inshakova, A. I. Goncharov // Studies in Computational Intelligence / ed. by E.G. Popkova. - Cham : Springer Science + Business Media, 2019. - Vol. 826. - P. 205-213.

\section{REFERENCES}

1. Ermakova E.P., Frolova E.E. Pravovoe regulirovanie cifrovogo bankinga $\mathrm{V}$ Rossii i zarubezhnyh stranakh (Evropejskij Sojuz, SShA, KNR) [Legal Regulation of Digital Banking in Russia and Foreign Countries (European Union, USA, China)]. Vestnik Permskogo universiteta [Perm University Bulletin], 2019, no. 46, pp. 606-625.

2. Inshakova A.O., Goncharov A.I. Imperativy finansovoj politiki v uslovijah cifrovizacii rossijskoj jekonomiki [Financial Policy Imperatives in the Context of Digitalization of the Russian Economy]. Bankovskoe Pravo [Banking Law]. Moscow, Jurist, 2018, no. 2, pp. 49-56.
3. Inshakova A.O., Goncharov A.I. Konosament $\mathrm{V}$ pravovom obespechenii vneshnetorgovoj dejatel'nosti: ot lichnoj vypiski do jelektronnogo kriptokoda [Bill of Lading in the Legal Support of Foreign Trade: From Personal Statement to Electronic Cryptocode]. Vestnik RUDN [RUDN Bulletin], 2019, vol. 23, no. 3, pp. 375-393.

4. Klinov A.O. Pravovoe regulirovanie kraudfandinga $\mathrm{v}$ Rossii i za rubezhom [Legal Regulation of Crowdfunding in Russia and Abroad]. Zakon [Law], 2018, no. 2, pp. 90-105.

5. Kotenko D.A. Kraudfanding - innovacionnyj instrument investirovanija [Crowdfunding is an Innovative Investment Tool]. Zakon [Law], 2014, no. 5, pp. 140-145.

6. Kuznecov V.A. Kraudfanding: aktualnye voprosy regulirovanija [Crowdfunding: Current Regulatory Issues]. Dengi i kredit [Money and Credit], 2017, no. 1, pp. 65-73.

7. Pismo Federalnoj nalogovoj sluzhby ot 25.11.2016 g. № SD-4-3/22415@. URL: http:// nalog.ru (accessed 20 November 2019).

8. Proekt Federalnogo zakona № 419090-7 "Ob alternativnyh sposobah privlechenija investicij (kraudfandinge)». URL: https://sozd.duma.gov.ru/ bill/419090-7.

9. Tropskaja S.S. Finansovyj rynok v uslovijah razvitija cifrovoj jekonomiki (finansovo-pravovoj aspekt) [Financial Market in the Context of the Development of the Digital Economy (Financial and Legal Aspect)]. Finansovoe Pravo [Financial Law], 2018, no. 8, pp. 28-33.

10. Federalnyj zakon ot 02.08.2019 № 259-FZ «O privlechenii investicij s ispolzovaniem investicionnyh platform $\mathrm{i}$ o vnesenii izmenenij v otdelnye zakonodatelnye akty Rossijskoj Federacii». Sobranie zakonodatelstva $R F, 2019$, Aug. 5 (no. 31), art. 4418.

11. Inshakova A.O., Goncharov A.I., Mineev O.A., Sevostyanov M.V. Amendments to the Civil Code of the Russian Federation: Contradictions of Theory and Practice. Contributions to Economics. Russia and the European Union: Development and Perspectives, 2017, no. XIII, pp. 147-153.

12. Goncharov A.I., Goncharova M.V. Digital Tokens in the Tools of Modern Foreign Trade Activities by Economic Entities of the BRICS Jurisdictions. Legal Concept $=$ Pravovaya paradigma, 2019, vol. 18, no. 3 . pp. 31-42. DOI: https://doi.org/10.15688/lc.jvolsu.2019.3.5.

13. Frolova E.E., Inshakova A.O., Dolinskaya V.V. The Concept and Legal Framework for Judging Corporate Conflicts on the US Financial Market. "Conflict-Free" Socio-Economic Systems: Perspectives and Contradictions. Bingley, West Yorkshire, 2019, pp. 101-108.

14. Inshakova A.O., Goncharov A.I., Kazachenok O.P. The Imperatives of Financial Policy 
in the Sphere of the Digital Economy: Impacts on Increasing Investment Activity and Tax Potential of Russian Regions. Proceedings of the International Scientific Conference "Competitive, Sustainable and Secure Development of the Regional Economy: Response to Global Challenges" (CSSDRE 2018). Amsterdam, Atlantis Press, 2018, pp. 337-342.
15. Kalinina A.E., Inshakova A.O., Goncharov A.I. Polysubject Jurisdictional Blockchain: Electronic Registration of Facts to Reduce Economic Conflicts. Ubiquitous Computing and the Internet of Things: Prerequisites for the Development of ICT. Studies in Computational Intelligence. Cham, Springer Science + Business Media, 2019, vol. 826, pp. 205-213.

\section{Information About the Author}

Denis E. Matytsin, Candidate of Sciences (Economics), Researcher, Department of Entrepreneurial Law, Civil and Arbitration Proceeding, Volgograd State University, Prosp. Universitetsky, 100,400062 Volgograd, Russian Federation,d_matytsin@ya.ru, kafedrappagp@volsu.ru, https://orcid.org/0000-0002-4038-4032

\section{Информация об авторе}

Денис Евгеньевич Матыцин, кандидат экономических наук, научный сотрудник кафедры предпринимательского права, арбитражного и гражданского процесса, Волгоградский государственный университет, просп. Университетский, 100, 400062 г. Волгоград, Российская Федерация, d_matytsin@ya.ru, kafedrappagp@volsu.ru, https://orcid.org/0000-0002-4038-4032 